
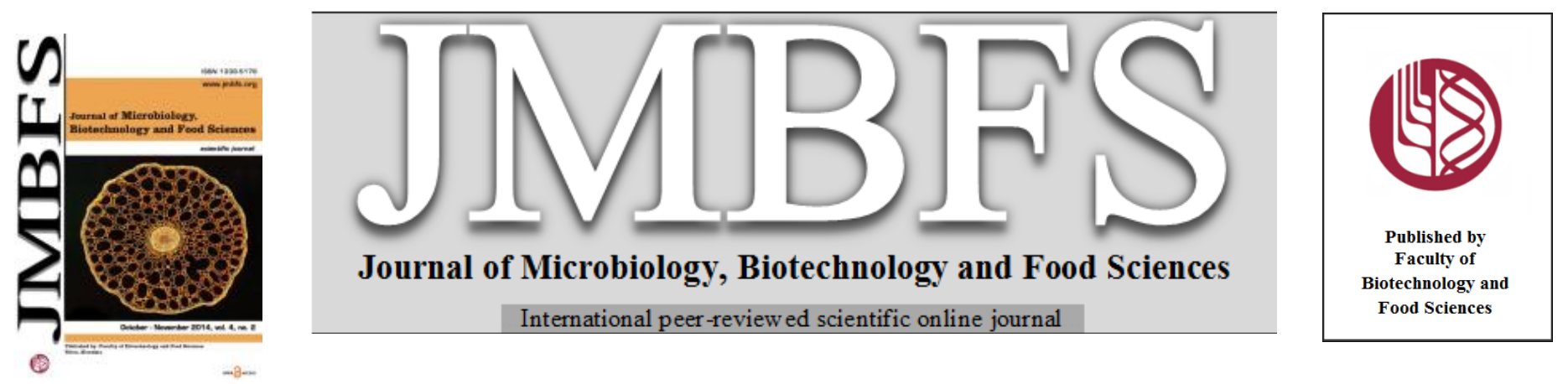

\title{
LIVE/DEAD YEAST VIABILITY STAINING AS A TOOL FOR IMPROVING ARTISANAL PILSNER BEER PRODUCTION
}

\section{Benedetta Bottari ${ }^{*}$, Giovanni Campari ${ }^{2}$, Monica Gatti $^{1}$}

\author{
Address(es): PhD Benedetta Bottari, \\ ${ }^{1}$ Department of Food Science, University of Parma, Parco area delle Scienze 49/A, 43124 Parma, Italy, +390521906528. \\ ${ }^{2}$ Birrificio del Ducato, Gruppo Italy s.r.l., 43011 Roncole Verdi di Busseto, Parma, Italy.
}

*Corresponding author: benedetta.bottari@unipr.it

doi: 10.15414/jmbfs.2014.4.2.174-178

\section{ARTICLE INFO}

Received 10. 6. 2014

Revised 22. 9. 2014

Accepted 22. 9. 2014

Published 1. 10. 2014

Regular article

open $\partial_{\text {AcCESS }}$

\section{ABSTRACT}

The production of an artisanal beer, made by brewers using traditional practices on a small scale, is founded on the empirical adjustment of parameters, including yeasts handling and serial repitching. The aim of this study was to monitor yeast viability during different stages of artisanal beer productions through the Live/Dead Yeast viability staining and to correlate it with fermentation dynamics in order to increase process standardization and to maintain the quality of final products. Yeast viability and fermentation activities were evaluated during seven fermentation cycles of an artisanal pilsner beer. Yeast inoculated with higher viability performed generally better in fermentation, resulting in faster sugar consumption, faster ethanol production and stability. Handling yeast and serial repitching based on Live/Dead viability measurements, could be the key way to ensure reliable manufacture of high quality beer and to improve process standardization particularly for microbreweries, where variability of production can be a challenging point.

Keywords: Artisanal beer, yeast viability, Live/dead yeast viability staining, fermentation activities

\section{INTRODUCTION}

Since the first records of beer production by mankind, many changes have been made that resulted in the modern beer-brewing process and many beer styles have developed over time (Lodolo et al. 2008). An alternative attitude and approach to brewing of flexibility, adaptability, experimentation and customer service, is represented by microbreweries. Micro or craft breweries have adopted a different marketing strategy than large, mass-market breweries, offering products that compete on the basis of quality and diversity, instead of low price and advertising. Despite all the changes, brewing yeast is always the main character in beer brewing (Lodolo et al. 2008). The impact of yeasts on the production and quality of beer is intimately linked to their viability and fermentation activities from the first pitching throughout the subsequent cycles of fermentation. Brewing is in fact unique within alcoholic beverage industry in that the yeast is not discarded after use but is maintained and reused a number of times (Powell $\boldsymbol{e t}$ al 2003). The physiological state of the inoculum coupled with the conditions established at pitch influence subsequent patterns of growth. Predicting the capacity of pitching yeast towards its subsequent fermentation performance is of key importance (Guido et al. 2004). In particular, inoculating worts with the correct number of yeast cells at the appropriate viability state is critical for consistent fermentation performance (Cahill et $\boldsymbol{a l}$. 1999). While yeasts cell number is routinely determined, yeast viability is a key parameter that should be measured more frequently. Furthermore, as yeast progresses through the brewing cycle of storage, pitching, fermentation, cropping and storage, it is subject to a number of stresses, thus, viability tests can be used not only to achieve a desired pitching rate but also to constantly check the quality of yeast that could affect subsequent fermentation performance. In fact, a key feature of any good brewhouse is reproducibility. Consumers will appreciate some variation in the beer in the interest of presumed authenticity but will not tolerate a taste too far from the one he likes and he has chosen a particular brand for. Whether the pitching yeast is brand new or derived from a previous fermentation, yeasts viability has been proven to play a key role in maintaining the reproducibility between different batches (Cahill et al. 1999, Boyd et al. 2002). Beer quality is strongly influenced by the biochemical performance of yeast during fermentation. Rate and efficiency of sugars utilization and ethanol yield, and consequently the character of the final product, can be affected by many factors, among which the yeast viability (Gibson et al. 2007). Cell viability is usually defined as the ability of a cell to reproduce and to form colony. It is conventionally measured using the laborious and time consuming culturing methods which are too slow to be of practical use. Moreover, colony counting does not reliably reports on the metabolic capacity of slow-growing or non dividing cells missing out the physiological processes other than those involved in cell division that can be of considerable practical importance (Millard et al. 1997). Other that being the ability of cells to grow, reproduce and interact with their immediate environment (Smart et al. 1999), viability is therefore ultimately linked to vitality, that is a measure of activity (D'Amore 1992), fermentation performance (Boulton 1991) and the capacity of recover from physiological stress (Smart 1996). Aim of this study was to monitor yeast viability by means of Live/Dead Yeast Viability staining during different stages of different artisanal beer productions and to correlate it with fermentation dynamics in order to increase process standardization and to maintain the quality of final product.

\section{MATERIAL AND METHODS}

\section{Brewing}

The samples analyzed in this study were obtained from different batches of VIÆMILIA, an artisanal pilsner beer produced in Roncole Verdi in the province of Parma (Italy). VIÆMILIA is brewed using only barley malts, water, hops (according to German purity law Reinheitsgebot of 1516) and yeast.

\section{Wort production}

Wort production took place in the brewhouse and started with mashing operations. Mashing method of VIÆMILIA followed the multi-step infusion system, which consists in mixing water with milled malts (mash-in) and heat the mash at different steps: 20 minutes at $52^{\circ} \mathrm{C}, 20$ minutes at $66^{\circ} \mathrm{C}$ and 25 minutes at $72^{\circ} \mathrm{C}$. After mashing, unhopped wort was separated from the undissolved solids, the spent grains or draff. Infusion mashing was carried out for 20 minutes in the mash tun. Then wort (liquid) was withdrawn from the mash and filtered through the bed of grist particles. When bright the wort was moved directly to a copper to be boiled with hops for 100 minutes. After boiling hop fragments were separated in a whirlpool tank. After cooling at $11,5{ }^{\circ} \mathrm{C}$ wort was aerated to provide oxygen for the yeast at initial stages of fermentation and transferred to fermentation tank where yeast pitching took place. 


\section{Fermentation}

Fermentations were led in cycles. For the first cycle a pure culture (W-34/70, purchased from UBERTI SRL, Venice, Italy) was used in dry form (trial a), while for each of next cycles yeast collected from the bottom of fermenter at the end of fermentation, was repitched into the following batch of wort. According to production needs, repitching was done either the same day (trails b, d, g) or after yeast storage up to three days at $4{ }^{\circ} \mathrm{C}$ (trials c, e, f). Primary fermentation was lead at $11,5^{\circ} \mathrm{C}$ to a final gravity of $2,5^{\circ} \mathrm{P}(1010 \mathrm{~g} / \mathrm{L})$, then green beer was racked to maturation tank where was slowly cooled to $2,5{ }^{\circ} \mathrm{C}$ and held at this temperature for three weeks. During the lagering dried hop cones were added to the beer to obtain a further extraction of the finest and more volatile aromas from hops. After dry hopping, mature beer (three weeks) was artificially carbonated and packed. VIÆMILIA was brewed with either single batch or double batch fermentation. Single batch brewing is a classical pils brewing while double batch brewing consists in the addition of fresh wort to beer in fermentation (at 23 hours).

\section{Sampling}

Seven fermentation cycles were monitored. Samples were obtained at 0, 16, 40, $64,88,112,136$ and 160 hours from single batch fermentations (a, b, e), and at 0 $16,21,24,40,64,88,112,136$ and 160 hours from double batch fermentations (c, $\mathrm{d}, \mathrm{f}, \mathrm{g})$. Time 0 is referred to inoculum before pitching. One more sample was collected after the top up (23 hours) for fermentation activities analysis.

\section{Yeast viability}

Aliquots of $1 \mathrm{ml}$ of each sample were centrifuged for $5 \mathrm{~min}$ at $10000 \mathrm{rpm}$, in order to separate cells from wort. Yeast viability has been determined by using the Live/Dead Yeast viability kit (MOLECULAR PROBES, Eugene, Oregon). This kit contains a two-colour fluorescent probe for yeast viability, FUN ${ } 1$, which exploits normal endogenous biochemical processing mechanisms that appear to be well conserved among different species of yeast and other fungi (Millard et al. 1997). After collection, cells were washed in sterile Millipore water and resuspended in $0.50 \mathrm{~mL}$ of sterile $\mathrm{GH}(2 \%$ glucose in $10 \mathrm{mM}$ Na-Hepes $\mathrm{pH}$ 7.2) $2.0 \mu \mathrm{L}$ of $10 \mathrm{mM} \mathrm{FUN}-1$ stock was added to each microcentrifuge tube and the cells were vortexed. Cells were then allowed to incubate with agitation at $30^{\circ} \mathrm{C}$ for $30 \mathrm{~min}$. Cells were then spun down and washed twice in sterile Millipore water. Stained yeast cells were examined under a Nikon Eclipse 80 epifluorescence microscope (NIKON, Tokyo, Japan) equipped with a C-SHG1 100 W mercury lamp. Nikon filter set B2A FITC was used for FUN1 ${ }^{\circledR}$ (excitation wavelength, 450-490 nm; emission wavelength, 500-520 nm). Nikon filter set G-2E/Cwas used for FUN1 ${ }^{\circledR}$ converted (excitation wavelength, 540/25 $\mathrm{nm}$; emission wavelength, $605 / 55 \mathrm{~nm}$ ).

At least 10 fields with approximately 20 cells in each were counted for each sample at a magnification of $\times 100$. For each field, fluorescent cells were counted and the resulting values were averaged. To express counts as cells $/ \mathrm{ml}$, the average values were multiplied by $5.21 \times 10^{8}$, a dilution factor to account for the coverslip area $\left(400 \mathrm{~mm}^{2}\right)$, the area of each field $\left(0.003072 \mathrm{~mm}^{2}\right)$, the volume of the sample deposited onto the slide $(10 \mu \mathrm{l})$, and the sample dilution. Nis Elements software (version 2.10 NIKON, Tokyo, Japan) was used for image analysis an cell counts. The software allowed separated images of yeasts cells with or without CIVS to be superimposed.

\section{Fermentation activities}

Fermentation activities were monitored determining sugars consumption and ethanol production. Maltose and Glucose consumption were assayed with Maltose/Sucrose/D-Glucose UV-method and D-Glucose UV method (BOEHRINGER MANNHEIM, R-BIOPHARM, Darmstadt, Germany), respectively. Ethanol production was determined with Ethanol UV-method (BOEHRINGER MANNHEIM, R-BIOPHARM, Darmstadt, Germany). After centrifugation and appropriate dilution, samples were analyzed according to manufacturer instructions. Glucose, maltose and ethanol amount are measured by means of their light absorbance at $340 \mathrm{~nm}$. Analyses were performed in triplicate and results, as mean values, were expressed as $\mathrm{g} / \mathrm{L}$, according to the general equation for calculating the concentrations provided on the kit technical sheet.

\section{RESULTS AND DISCUSSION}

Dynamics of yeast viability are shown in figure 1, where results for single batch $(\mathrm{a}, \mathrm{b}, \mathrm{e})$ and double batch $(\mathrm{c}, \mathrm{d}, \mathrm{f}, \mathrm{g})$ brewed samples are presented in separated columns.

Yeast viability has been measured by Live/Dead Yeast viability kit (MOLECULAR PROBES, Eugene, Oregon), which performances in counting live and dead cells have previously shown to be in good agreement with traditional enumeration of the colonies recovered on plates (Andorrà $\boldsymbol{e t}$ al. 2010), and to give more accurate results than the most commonly used methylene blue staining (Heggart et al. 2000). According with general breweries protocols (Briggs et al. 2004), the initial yeast concentration was relatively high and the subsequent growth extent modest. The total number of cells was in the range of $10^{8}$ to $10^{9}$ cell $/ \mathrm{ml}$ for each batch of fermentation. Yeast viability was found to be variable according to the selected empirical parameters of brewing. Viability was low at the beginning of the first fermentation, when dry inoculum had been used (trial a), confirming that the culture must revert to its fully functional state and adapt to its new environment before it could perform efficiently (Finn and Stewart, 2002). Adaptation of cells to brewing conditions resulted in higher viability, well maintained during all the batch of fermentation. The subsequent cycles yeast viability has been affected by yeast handling before re-pitching. Viability rate was higher when yeast was directly reused after the previous fermentation end (trials b, d, g), while an increased number of damaged cells was found when yeast slurry was stored at $4^{\circ} \mathrm{C}$ after cropping (Fig 1 trial c, e, f) Typically, the yeast cropped from the fermentation vessel to be used for serial repitching is the centre-top portion, theoretically comprising middle-aged and virgin cells that have been suggested to represent the most active portion of the pitch population in terms of rapid growth and yeast biomass production (Ginovart et $\boldsymbol{a l}$. 2011). These results are in agreement also with Cahill $\boldsymbol{e t}$ al. (1999) who affirmed that during prolonged storage, the quality of the yeast deteriorates and the percentage of viability decreases accordingly. As observed in previous works (Guido et al. 2004), yeast showed to be able to recover its viability throughout fermentation. However, viability has a greater importance in the earlier phases of fermentation, when the fermentative capacity is not due to the yeast growth or multiplication, but instead to the intense metabolic activity and, thus, to the viability of the pitched yeast (Guido et al. 2004). The initial conditions of the seed yeast cells influence not only population growth, but also the rate of nutrient uptake and ethanol production (Ginovart et al. 2011).

It is known that, during fermentation, the yeast sugar up-take follows the route of simplest sugars like glucose first, followed in increasing order of complexity by disaccharides (maltose) and trisaccharides (maltotriose) excluding maltotetraose and other dextrins (Lodolo et al. 2008). Glucose and maltose consumption and ethanol production rates, are reported in figure 2 , with single batch $(\mathrm{a}, \mathrm{b}, \mathrm{e})$ and double batch brewed (c, d, f, g) trials presented in separated columns. 
A

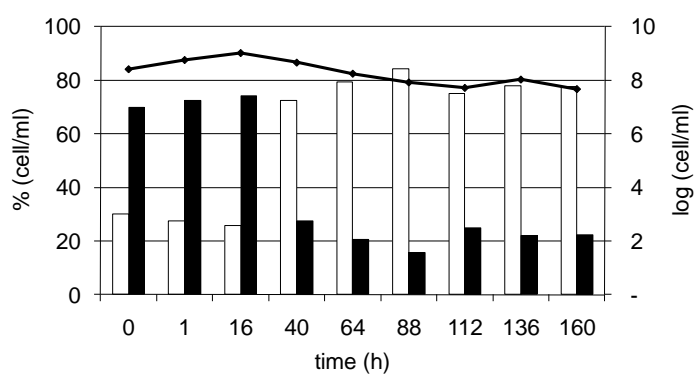

B

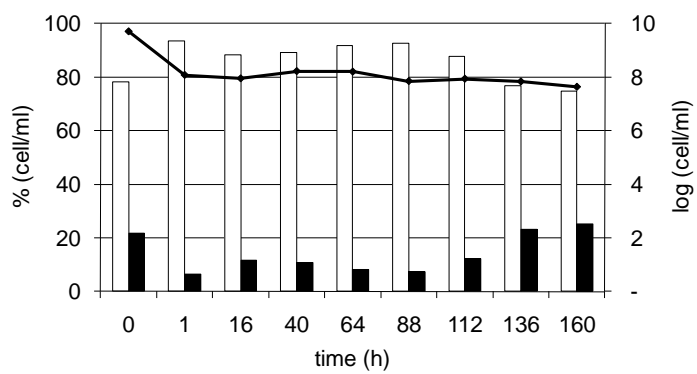

E

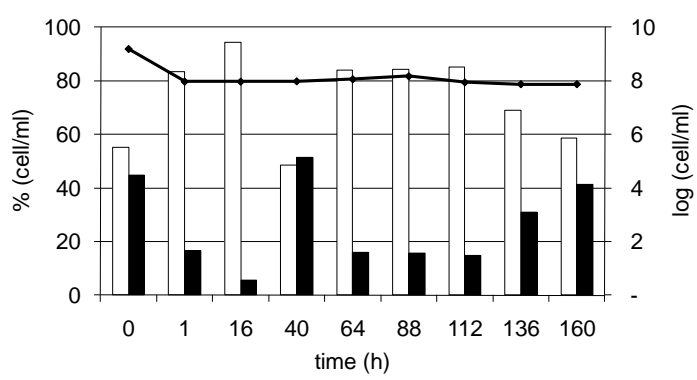

C

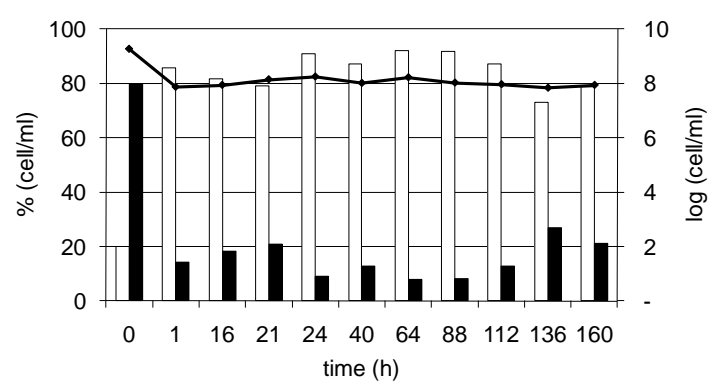

D

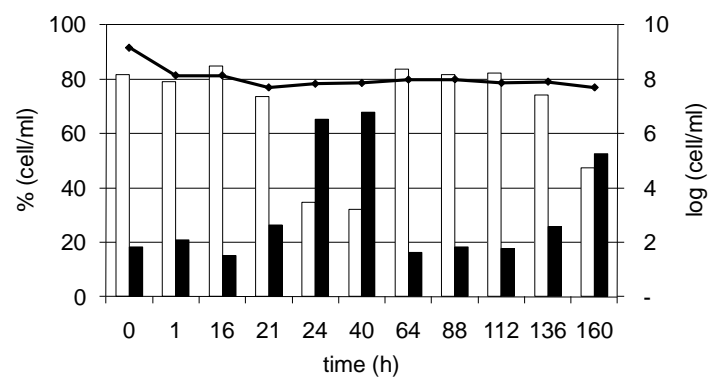

$\mathbf{F}$

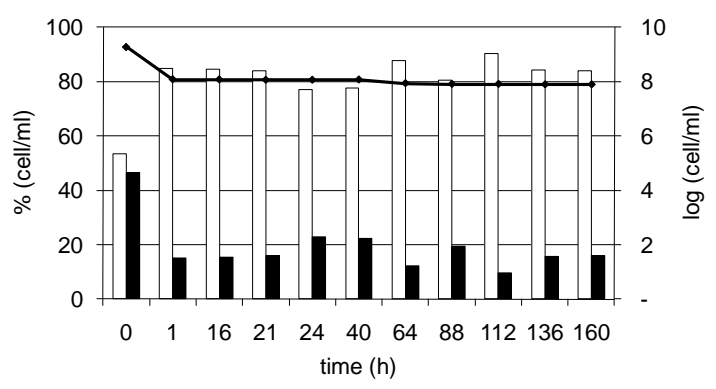

G

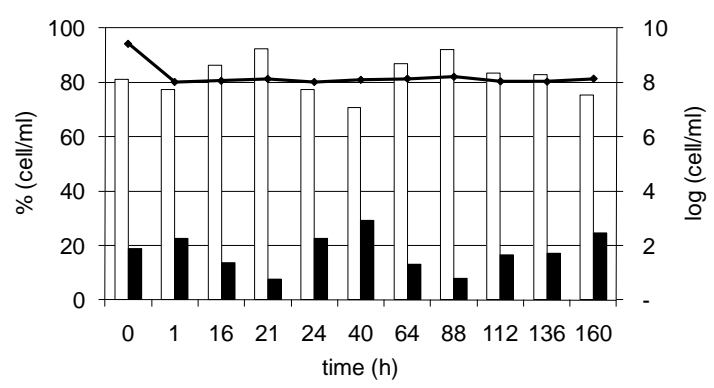

Figure 1 Yeast viability in the 7 considered batches. a, b, e are single batch brewing; c, d, f, g are double batch brewing. Pitching has been done with a) dry yeast; b, d, g) fresh cropped yeast; c, e, f) $4^{\circ} \mathrm{C}$ - stored cropped yeast $\square$ percentage of viable cells; $\mathbf{\square}$ percentage of non viable cells. [-] Total number of cells 
A
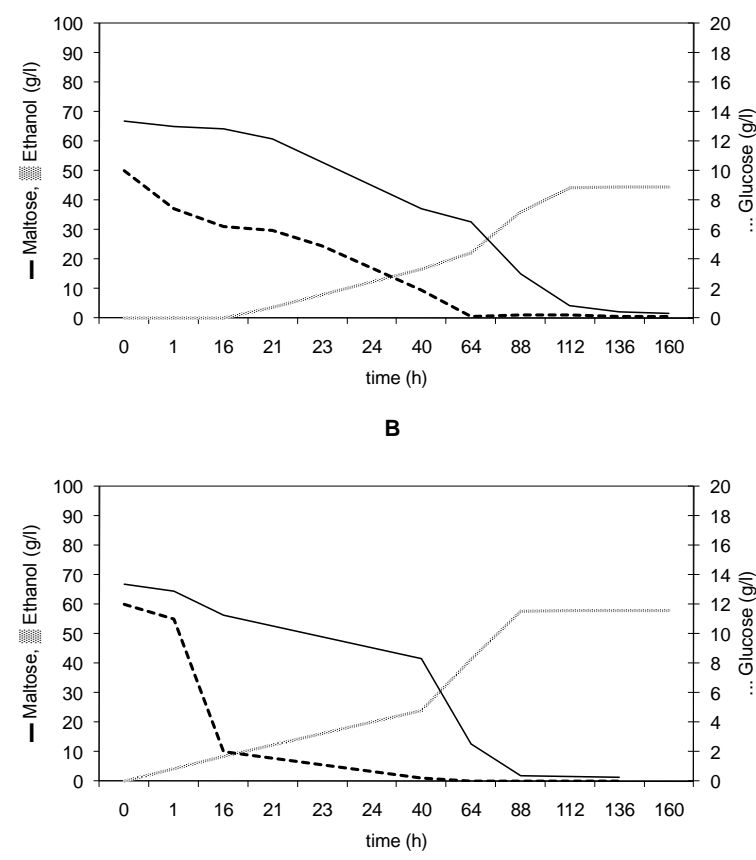

E
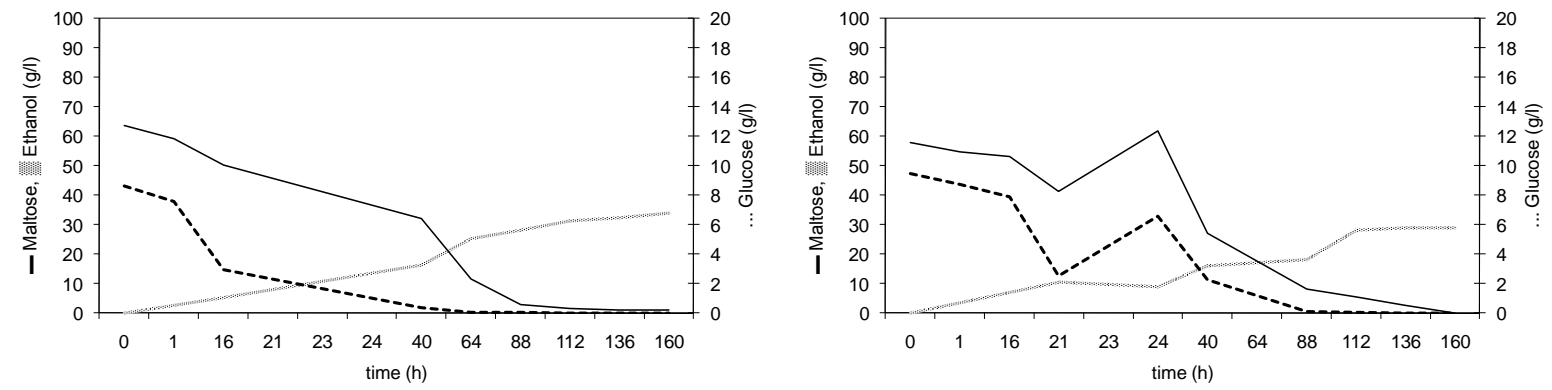

G

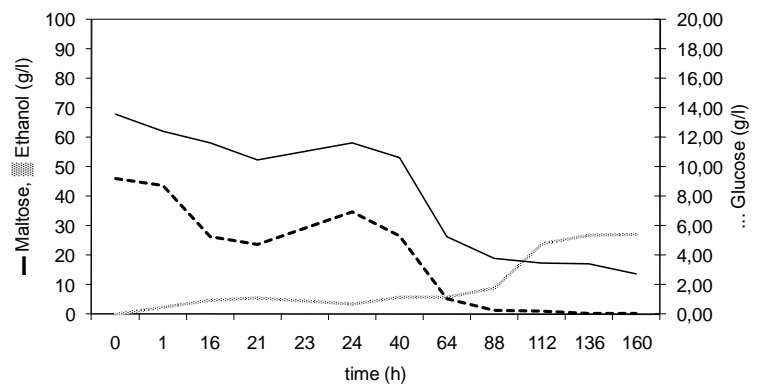

Figure 2 Glucose [---] and maltose [-] consumption; ethanol [ " brewing; c, d, f, g are double batches brewing. Pitching has been done with a) dry yeast; b, d, g) fresh cropped yeast; c, e, f) $4^{\circ} \mathrm{C}$ stored cropped yeast.

Sugar and ethanol fluctuations at 21-40 hours in double batch brewed samples, were expected as a consequence of fresh wort addition to beer in fermentation, resulting in higher amount of available sugars and in ethanol dilution. For the single batch brewed trials, when the viable cells percentage in the inoculum was higher than $50 \%$, (Fig 2 trials b, e) we observed a faster sugar consumption: e.g. 40 hours for glucose and 88 hours for maltose consumption in trial b versus 64 and 136 hours respectively in trial a. Faster sugar consumption and the resultant gradual ethanol production, led to a 24 hour shorter production process (Fig 2 trials b, e). This is in agreement with Ginovart et al. (2011) who demonstrated that enhanced glucose consumption rate and ethanol productivity in specific characteristics of the initial yeast cells, implied higher fermentation capability, which is beneficial for industrial ethanol fermentation. For the double batch brewed trials, a higher percentage of viable cells (Fig 2 trials d) in the inoculum corresponded to a greater consumption of sugars before the top up and to a faster reaching of ethanol production and yield stability. However, although the most of pitched cells were viable, sugars up-take in trials $\mathrm{f}$ and $\mathrm{g}$ was lower than in trials $\mathrm{d}$ (Fig 2), as a probable consequence of the approaching of serial repitching termination. In agreement with Powell et al. (2003), this seems to suggest that towards the end of times of yeast reuse, fermentation capability is mainly an outcome of cell age rather than a viability defect. These results are in good agreement also with Ginovart et al. (2001) who concluded that seeding a fermentation with yeast consisting primarily of aged cells would result in an extended lag phase in the fermenter due to slow progression through the cell cycle. Furthermore, it is known that serial repitching cycles cause changes in the activity of yeast cells, which are responsible for prolonged fermentation and strong flavour beer production (Kobayashi et al. 2007). Anyhow, in both single batch and double batch brewed trials, yeast inoculated with higher viability performed generally better in fermentation. More viable yeast in batches $b$ and $d$ 
fermented more rapidly in the early stages of the fermentations. This is in agreement with Guido et al. (2004), who reported that selecting a yeast in a good physiological state, a rapid fermentation may be achieved, in order to produce a beer with the maximum attainable ethanol content, consistent with the overall flavour balance of the product. Fermentation of worts inoculated with dry yeast (Trial a) or with stored cropped yeast (Trials c, e, f) have been completed more slowly. Even though the final ethanol yield was not affected by early fermentation rates, pitching yeast with a lower viability percentage caused a delay in fermentation start (Trials a, c, f). Other authors (Ginovart et al. 2011) have previously shown that, despite a similar level of ethanol is achieved in the end, the population growing from old inoculated cells has the slowest ethanol production. Longer fermentation can cause a "bottle neck" in the process, which is of particular significance on a small artisanal brewery, that is not able to solve the problem increasing further size or number of fermenters (Lodolo et al. 2008) An extended fermentation time has a direct impact on plant efficiency, with subsequent financial implications (Powell et al. 2003). Furthermore, if the performance of the fermentation does not fall within the normal range in terms of duration and extent of yeast growth, the resultant beer could not be within specification. Although chemical analysis have not been undertaken in this study, Guido et al. (2004) showed that yeast physiological conditions affect severa quality parameters, such as the concentration of beer volatile esters and higher alcohols and the beer flavour stability.

Beer is hard to spoil and has a remarkable microbiological stability because it is an unfavourable medium for many microorganisms. This is due to the presence of ethanol, hop bitter compounds, the high content of carbondioxide, the low $\mathrm{pH}$ the extremely reduced content of oxygen and the presence of only traces of nutritive substances such as glucose, maltose and maltotriose. In fact, these latter carbon sources are usually almost completely metabolized by yeast during a fas and correct fermentation (Sakamoto et al. 2003). If the carbon sources are not completely depleted, they remain available for spoilage microorganisms, like lactic acid bacteria, that could develop more easily.

\section{CONCLUSION}

Despite brewing parameters in an artisanal brewery are often bound to empirical factors such as fermenter availability and consumer demand, brewer should keep on chasing reproducibility and process standardization in order to guarantee a constant high quality of the final product. To this aim, serial repitching, whereby yeast cropped at the end of fermentation is reused in subsequent fermentations, is a process worth of study (Ginovart $\boldsymbol{e t}$ al. 2011). The response to the numerous stresses to which the yeast is exposed, from fermentation of wort and through handling between fermentations, is crucial for beer production but also for maintaining the fermentation fitness of yeast for subsequent fermentations (Gibson et al. 2007). Live/Dead Yeast viability staining gives in short time accurate results on the viability state of the yeast to be pitched. Studying yeast viability and fermentation performance expressed as sugar up-take and ethano production, here we provided evidence to suggest that yeast viability could be the key way to improve process standardization particularly for microbreweries, where variability of production can be high. Periodical evaluation of this parameter, could be the starting point for an effecting yeast management program, with the ultimate goal of the production of more consistent and higher quality beer.

Acknowledgments: The authors are grateful to Dr. Elena Panizza and Dr Roberto Manotti for their technical contribution.

\section{REFERENCES}

ANDORRÀ, I., ESTEVE-ZARZOSO, B., GUILLAMÓN, J.M., MAS, A. 2010 Determination of viable wine yeast using DNA binding dyes and quantitative PCR. International Journal of Food Microbiology, 144, 257-262. http://dx.doi.org/10.1016/j.ijfoodmicro.2010.10.003

BOULTON, C. (1991). Yeast management and the control of brewery fermentations. Brewers guardian, 120, 25-29.

BOYD, A.R., GUNASEKERA, T.S., ATTFIELD, P.V., SIMIC, K., VINCENT S.F., VEAL D.A. 2002. A flow-cytometric method for determination of yeas viability and cell number in a brewery. FEMS Yeast Research, 3, 11-16. http://dx.doi.org/10.1111/j.1567-1364.2003.tb00133.x

BRIGGS, D.E., BOULTON, C.A., BROOKES, P.A., STEVENS, R. 2004 Brewing science and practice. Woodhead Publishing Limited and CRC Press LLC Abington Hall, Abington Cambridge CB1 6AH, England.

CAHILL, G., WALSH, P.K, DONNELLY, D. 1999. Improved control of brewery yeast pitching using image analysis. Journal of American Society Brewing Chemist, 57, 72-78. http://dx.doi.org/10.1094/ASBCJ-57-0072

D'AMORE, T. 1992. Cambridge prize lecture - Improving yeast fermentation performance. Journal of the Institute of Brewing, 98, 375-382.

FINN, D.A. \& STEWART, G.G. 2002. Fermentation characteristics of dried brewers yeast: effect of drying on flocculation and fermentation. Journal of $\begin{array}{llll}\text { American Society Brewing Chemist, } & 60, & 135-139\end{array}$ http://dx.doi.org/10.1094/ASBCJ-60-0135
GIBSON, B.R., LAWRENCE, S.J., LECLAIRE, J.P.R., POWELL, C.D. SMART, K.A. 2007. Yeast response to stresses associated with industria brewery handling. FEMS Microbiology Review, 31, 535-569. http://dx.doi.org/10.1111/j.1574-6976.2007.00076.x

GINOVART, M., PRATS, C., PORTELL, X., SILBERT, M. 2011. Analysis of the effect of inoculum characteristics on the first stages of a growing yeast population in beer fermentations by means of an individual-based model. Journal of Industrial Microbiology and Biotechnology, 38, 153-165. http://dx.doi.org/10.1007/s10295-010-0840-4

GUIDO, L.F., RODRIGUES, J.A., GONCALVES, C.R., BARROS, A.A. 2004 The impact of the physiological condition of the pitching yeast on beer flavour stability: an industrial approach. Food Chemistry, 87, 187-193. http://dx.doi.org/10.1016/j.foodchem.2003.10.033

HEGGART, H., MARGARITIS, A, STEWART, R.J., PILKINNGTON, H., SOBCZAK, J., RUSSELL, I. 2000. Measurement of brewing yeast viability and vitality: a review of methods. Master Brewers Association of the Americas Technical Quarterly, 37, 409-430.

KOBAYASHI, M., SHIMIZU, H., SHIOYA, S. 2007. Physiological analysis of yeast cells by flow cytometry during serial repitching of low malt beer fermentation. Journal of Bioscience and Bioengineering, 5, 451-456. http://dx.doi.org/10.1263/jbb.103.451

LODOLO, E.J., KOCK, J.L.F., AXCELL, B.C., BROOKS, M. 2008. The yeast Saccharomyces cerevisiae- the main character in beer brewing. FEMS Yeast Research, 8, 1018-1036. http://dx.doi.org/10.1111/j.1567-1364.2008.00433.x

MILLARD, P.J., ROTH, B.L., TRUONG THI, H., YUE, S.T., HAUGLAND, R.P. 1997. Development of the FUN-1 family of fluorescent probes for vacuole labelling and viability testing of yeasts. Applied and Environmental Microbiology, 63, 2897-2905

POWELL, C.D., QUAIN, D.E., SMART, K.A. 2003. The impact of brewing yeast cell age on fermentation performance, attenuation and flocculation. FEMS Yeast Research, 3, 149-157. http://dx.doi.org/10.1016/S1567-1356(03)00002-3

SAKAMAOTO, N. \& KONINGS, V.N., 2003. Beer spoilage bacteria and hop resistance. International Journal of Food Microbiology, 89, 105-124 http://dx.doi.org/10.1016/S0168-1605(03)00153-3

SMART, K. 1996. Nutritional requirements and performance of yeast. In Monograph of the XXIV EBC symposium on immobilized yeast applications in the brewing industry. Carl Getranke-Fachrul, Nurnberg, 146-155.

SMART, K., CHAMBERS, K., LAMBERT, I., JENKINS, C. 1999. Use of methylene violet procedures to determine yeast viability and vitality. Journal of American Society Brewing Chemist, 57,18-23. http://dx.doi.org/10.1094/ASBCJ57-0018 